\title{
West-Palearctic species of the genus Neurigona Rondani (Diptera: Dolichopodidae)
}

\section{Западно-палеарктические виды рода Neurigona Rondani (Diptera: Dolichopodidae)}

\author{
I.Ya. Grichanov \\ И.Я. Гричанов
}

All-Russian Institute of Plant Protection, Podbelskiy roadway, 3, St. Petersburg, Pushkin 196608 Russia. E-mail: grichanov@mail.ru Всероссийский институт защиты растений, шоссе Подбельского, 3, Санкт-Петербург-Пушкин 196608 Россия.

KEY WORDS: Diptera, Dolichopodidae, Palearctic region, Neurigona, new species, new synonym, key.

КЛЮЧЕВЫЕ СЛОВА: Diptera, Dolichopodidae, Палеарктика, Neurigona, новые виды, новый синоним, определитель.

ABSTRACT. West-Palearctic species of the genus Neurigona Rondani, 1856 are reviewed. New species $N$. solodovnikovi Grichanov sp.n. from Morocco and $N$. meironensis Grichanov sp.n. from Israel are described and illustrated. $N$. verrichterae Negrobov et Fursov, 1988 is placed in synonymy to $N$. suturalis (Fallén, 1823) (syn.n.). A check list and revised key to WestPalearctic species of this genus are provided.

РЕЗЮМЕ. Составлен обзор западно-палерктических видов рода Neurigona Rondani, 1856. Даны описания и фотографии N. solodovnikovi Grichanov sp.n. из Марокко и N. meironensis Grichanov sp.n. из Израиля. N. verrichterae Negrobov et Fursov, 1988 сведён в синонимы к $N$. suturalis (Fallén, 1823) (syn.n.). Приведён список и определитель западнопалерктических видов рода.

\section{Introduction}

The genus Neurigona Rondani, 1856 (= Saucropus Loew, 1857) numbers 153 species distributed worldwide [Wang et al., 2007], but being poorly represented in Afrotropical and Australian Regions. Grichanov [2000, 2006] excluded Afrotropical Saucropus cyanescens Loew, 1858 and S. univittatus Loew, 1858 from the genus and doubted a record of Australasian $N$. angulata De Meijere, 1916 on Seychelles (female only). The genus seems to be replaced in Afrotropics with the related Tenuopus Curran, 1924; nevertheless, the author of this paper saw a female of true Neurigona collected from central Africa. The last key to Palearctic species of the genus was published by Negrobov and Fursov [1988]. Later two species were described from West Palearctic [Negrobov \& Tsurikov, 1990; Pârvu, 1996]. Recently many species have been described or recorded from China, and Wang et al. [2007] have compiled a key to males of 22 species of the genus from
Chinese mainland, with the exception of Palearctic $N$. zhangae Wang, Yang and Grootaert, 2006. Many species are known only from their type localities, while others are confined to certain territories of the Palearctic Region.

Treating collections of the Natural History Museum of Denmark (ZMUC) and the Zoological Museum of Tel-Aviv University, Israel (TAU), I have found new material on the genus Neurigona. Descriptions of two new species from Israel and Morocco are given in this paper. A check list and revised key to West-Palearctic species of the genus is here provided. Other material has been examined in the collection of the Zoological Institute, St. Petersburg (ZIN). The specimens were studied and illustrated with ZEISS Discovery V-12 stereomicroscope and AxioCam MRc5 camera. Morphological terminology follows Grichanov [2007] and Cumming and Wood [2009]. The relative lengths of the podomeres should be regarded as representative ratios and not measurements. Body length is measured from the base of the antenna to the tip of epandrium. Wing length is measured from the base to the wing apex. Male genitalia were macerated in $10 \% \mathrm{KOH}$. Figures showing the male genitalia in lateral view are oriented as they appear on the intact specimen (rotated $180^{\circ}$ and lateroflexed to the right), with the morphologically ventral surface of the genitalia facing up, dorsal surface down, anterior end facing right and posterior end facing left. Distribution of known species follows those of Negrobov [1991] and Grichanov [2006, 2007].

\section{Systematics}

\section{Genus Neurigona Rondani}

Neurigona Rondani, 1856: 142

Saucropus Loew, 1857: 41

REMARK. See diagnosis and discussion in Negrobov and Fursov [1988] and Naglis [2003]. Included species from West Palearctic region: 
abdominalis (Fallén, 1823: 21)

[Dolichopus] [Bezzi, 1903: 292].

TYPE LOCALITY: not given [Sweden].

DISTRIBUTION: Czech, Denmark, Finland, Germany, Latvia, Lithuania, Norway, Poland, Russia: Karelia, Krasnodar, St.Petersburg, Pskov; Sweden, UK.

biflexa Strobl, in Czerny \& Strobl, 1909: 183.

TYPE LOCALITY: Spain: "Algeciras, Fuente Teja bei Escorial".

DISTRIBUTION: Austria, Bulgaria, France, UK, Poland, Portugal, Spain.

cilipes (Oldenberg, 1904: 71)

[Saucropus]

TYPE LOCALITY: Italy: "Macugnaga auf der Ostseite de Monte Rosa".

DISTRIBUTION: Germany, Italy, Romania, Slovakia, Switzerland.

dobrogica Pârvu, 1996: 265.

TYPE LOCALITY: Romania: Constanșa.

DISTRIBUTION: Romania.

erichsoni (Zetterstedt, 1843: 613) 184]

[Dolichopus] [Schiner, in: Redtenbacher \& Schiner, 1862 292]

inaequalipes (Zetterstedt, 1843: 613) [Argyra] [Bezzi, 1903

TYPE LOCALITY: Sweden: "Scania: Lund, Silfakra, Röstanga, Lindholmen, Esperöd, Ostrogothia ad Gusum, Gottenvik, Jonsberg, Gottlandia ad Nähr, insula Furillen".

DISTRIBUTION: Austria, Belgium, Czech, Denmark, Estonia, France, Germany, Hungary, Iran, Netherlands, Norway, Poland, Romania, Russia: Adygea, Alania, Krasnodar, Moscow; Sweden, Switzerland, Ukraine: Cherkasy, Kharkiv; "Yugoslavia".

febrilata Negrobov et Fursov, 1988: 406.

TYPE LOCALITY: Krasnodar Terr., Caucasian Reserve, Aishkha pass.

DISTRIBUTION: S Russia: Krasnodar

helva Negrobov et Tsurikov, 1990: 35.

TYPE LOCALITY: Krasnodar Terr., Khosta env. DISTRIBUTION: S Russia: Krasnodar.

lineata (Oldenberg, 1904: 73)

[Saucropus].

TYPE LOCALITY: Germany: Worlitzer Forst (AnhaltDessau).

DISTRIBUTION: Belgium, Germany, Romania, Russia: Ryazan.

longipes Becker, 1918: 309

[Neurogona].

TYPE LOCALITY: Russia: "Ural"

DISTRIBUTION: Russia: Ural.

meironensis Grichanov, sp.n.

TYPE LOCALITY: Israel: Mt. Meiron. DISTRIBUTION: Israel.

nubifera (Loew, 1869: 302)

[Saucropus] [Strobl, 1898: 422]

TYPE LOCALITY: "Griechenland".

DISTRIBUTION: Greece; "Yugoslavia". pallida (Fallen, 1823:21)

[Dolichopus] [Loew, 1857: 41].

TYPE LOCALITY: Sweden: Scania [=Skane].

DISTRIBUTION: Austria, Belarus, Belgium, Czech, Denmark, Estonia, Finland, France, Germany, Greece, Hungary, Ireland, Italy, Latvia, Lithuania, Netherlands, Norway, Poland, Romania, Russia: Karelia, Karachai-Cherkessia, Lipetsk, St.Petersburg, Voronezh; E Russia: Krasnoyarsk, Orenburg, Tomsk; Slovakia, Sweden, Switzerland, UK, Ukraine: Crimea, Kharkiv.

pseudolongipes Negrobov, 1987: 414.

TYPE LOCALITY: Russia: Krasnodar Terr., Caucasian Reserve, Pshekish Mt.

DISTRIBUTION: Abkhazia; S Russia: Adygea, Karachai-Cherkessia, Krasnodar.

punctifera Becker, 1907: 103

TYPE LOCALITY: Algeria: Constantine.

DISTRIBUTION: Algeria

quadrifasciata (Fabricius, 1781: 448)

[Musca] [Rondani, 1856: 142].

quadrivittata (Macquart, 1827: 30) [Porphyrops]

TYPE LOCALITY: Germany.

DISTRIBUTION: Austria; Belarus: Minsk; Belgium, Czech, Denmark, Estonia, Finland, France, Germany, Hungary, Italy, Latvia, Lithuania, Netherlands, Norway, Poland, Romania, Russia: Karelia, St.Petersburg, Pskov, Tambov, Voronezh; E Russia: Urals, Krasnoyarsk, Baikal; Slovakia, Sweden, Switzerland; UK, Ukraine: Kiev.

semilata Negrobov et Fursov, 1988: 407.

TYPE LOCALITY: Russia: Krasnodar Terr., Caucasian Reserve, Guzeripl.

DISTRIBUTION: S Russia: Adygea, Krasnodar.

solodovnikovi Grichanov, sp.n.

TYPE LOCALITY: Morocco: 40 km S Larache. DISTRIBUTION: Morocco.

subcilipes Negrobov et Fursov, 1988: 409.

TYPE LOCALITY: Russia: Krasnodar Terr., Caucasian Reserve, Tegenya cordon.

DISTRIBUTION: S Russia: Adygea, Krasnodar.

suturalis (Fallén, 1823: 21)

[Dolichopus] [Loew, 1857: 41].

verrichterae Negrobov et Fursov, 1988: 411, syn. nov.

TYPE LOCALITY: Sweden: "Esperod".

DISTRIBUTION: Austria, Belgium, Czech, Denmark, Finland, France, Georgia, Germany, Hungary, Italy, Netherlands, Norway, Poland, Romania; Russia: Krasnodar, Krasnoyarsk, St.Petersburg; Slovakia, Sweden, Switzerland, UK, "Yugoslavia".

unicolor Oldenberg, 1916: 190

[Neurogona].

TYPE LOCALITY: Romania: Herkulesbad [= Baile Herculane].

DISTRIBUTION: Romania.

uralensis Becker, 1918: 311

[Neurogona].

TYPE LOCALITY: Russia: "Ural”.

DISTRIBUTION: Russia: Ural 


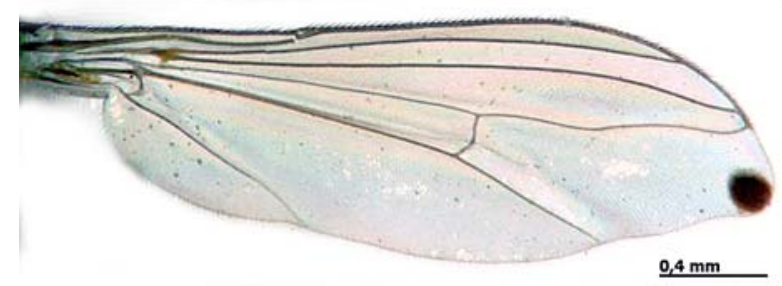

1
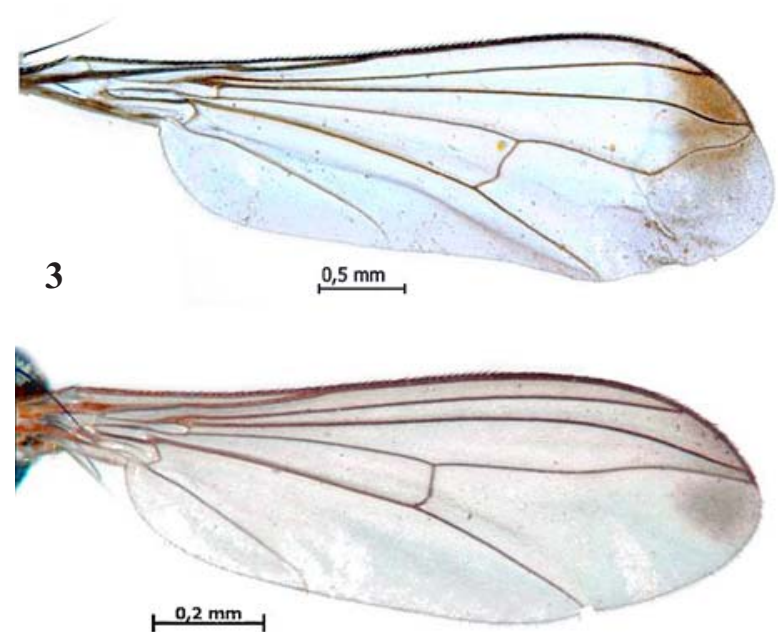

5

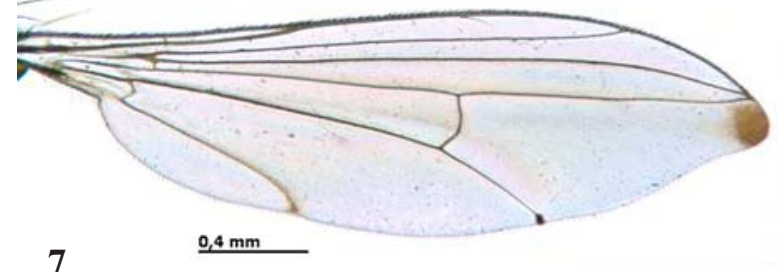

7

Neurigona solodovnikovi Grichanov, sp.n.

Figs $1-2,8,10,14$

TYPE MATERIAL. Holotype $\sigma^{7}$, Morocco: $40 \mathrm{~km} \mathrm{~S}$ Larache, 0-20 m, 23-24.IV.1989 [ZMUC]. Paratypes: $20^{7} 0^{7}$, 3 우, the same locality as holotype [ZMUC].

DESCRIPTION. Male. Length $(\mathrm{mm})$ : body 4.0 , wing 4.0 , antenna 0.9 , hypopygium 0.7 . Head metallic green with pale grey pollen; face black with dense pale pollen. Face slightly narrowing downward, eyes narrowly separated on middle portion of face. One pair of ocellars black and strong, 1 pair of verticals black and strong, 1 pair of postverticals white, long and strong, postverticals not longer than verticals; postocular bristles entirely pale. Antenna brownish yellow; postpedicel about as long as wide; stylus brown, middorsal, $4 \mathrm{x}$ longer than postpedicel, with short basal segment. Proboscis yellowish brown with pale hairs; palpus yellow with pale hairs.

Thorax: dark metallic green with pale grey pollen; humerus with pale yellow spot; scutellum dark yellow with small basal black spot in middle; metapleuron pale yellow. Hairs and bristles on thorax mainly black. 6 long strong dorsocentrals, 9-10 paired acrostichals, 1 long humeral bristle and 1 short adjacent pale hair, 1-2 sutural, 2 notopleural, 2 supraalar bristles. Propleuron with 1-2 pale hairs on upper portion (proepimeron) and 1 yellow bristle on lower portion

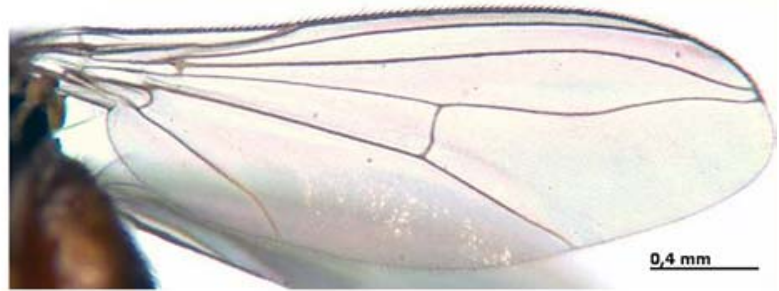

2
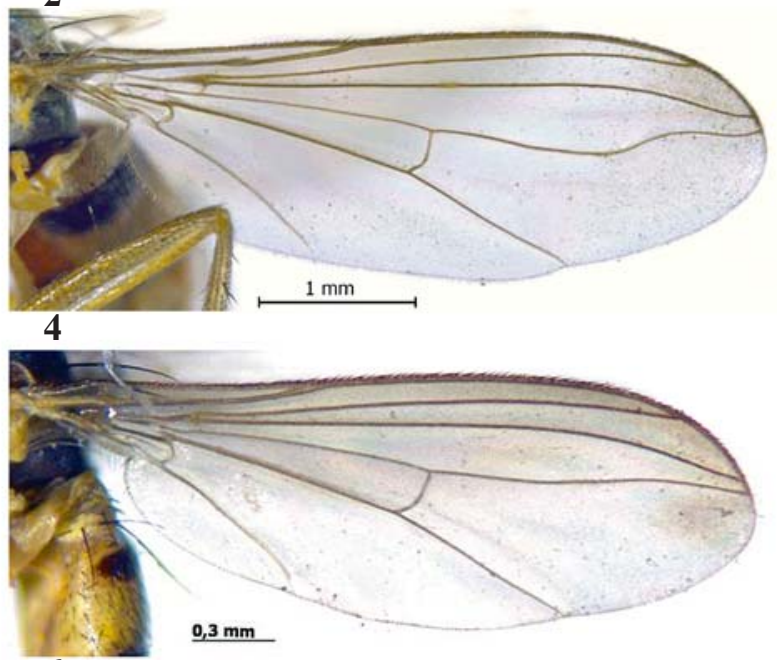

6

Figs 1-7. Neurigona spp., wing: 1-2 - N. solodovnikovi Grichanov, sp.n.; 3-4 - N. meironensis Grichanov, sp.n.; 5-6 Neurigona nubifera (Loew); 7 - Neurigona punctifera Becker; 1, 3, 5, 7 - males, 2, 4, 6- females.

Рис. 1-7. Neurigona spp., крыло: 1-2 - N. solodovnikovi Grichanov, sp.n.; 3-4 - N. meironensis Grichanov, sp.n.; 5-6Neurigona nubifera (Loew); 7 - Neurigona punctifera Becker; 1 , 3, 5, 7 - самцы, 2, 4, 6 - самки.

(proepisternum). Scutellum with 2 pairs of bristles, apical pair long and strong, but basal pair short and hair-like.

Legs: yellow; coxae yellow; fore tarsus brown-black from middle of basitarsus; mid and hind tarsomeres 2-5 brownish to brown. Hairs and bristles on legs mainly black. Fore coxa with pale hairs and 3-4 yellow to brown-black bristles on antero-apical portion; mid coxa with black hairs and 2-3 black anterior and apical bristles; hind coxa with 1 black outer bristle at middle. Fore and mid femora with microscopic pale hairs ventrally. Fore tibia devoid of bristles, with mainly pale setulae except 2 rows of black setulae on dorsal surface; mid tibia with 2 anterodorsal, 2 posterodorsal, 2-3 anteroventral, 2 posteroventral, 3 apical black bristles; hind tibia with 3 anterodorsal, 3 posterodorsal, 3 short ventral setae, apically with yellow comb of hairs and 3 black bristles. Fore tarsus with pale short ventral cilia on segments 2-4; tarsomeres 4-5 flattened ventrally; fore segment 4 with basal half somewhat swollen; tarsomere 5 with short black claws (about half as long as tarsomere 5) and 2 long apicodorsal setae (longer than tarsomere 5). Mid tarsomere 1 shorter than tibia, with 6-7 short ventrals. Hind tarsomeres 1-3 each with short ventrals; hind tarsomere 1 apically with yellow comb of hairs. Fore leg length ratio (from tibia to tarsomere 5): 64/37/10/8/7/5, mid leg: 83/64/ 23/16/9/6, hind leg: 110/30/35/16/12/8. 

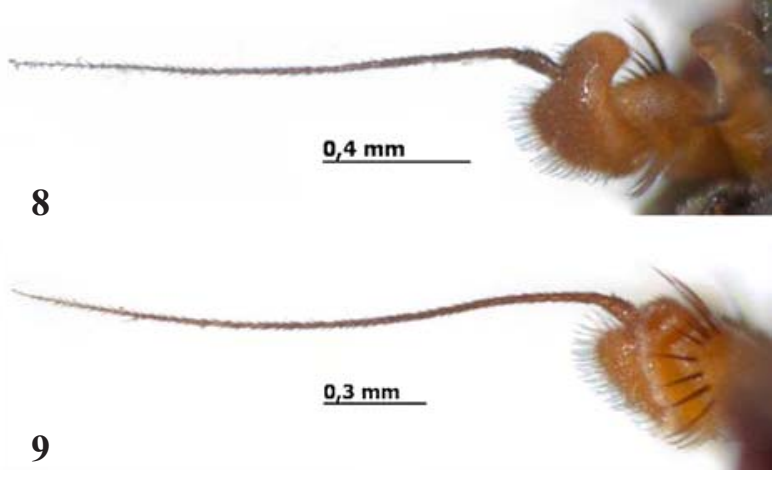

Figs 8-9. Neurigona spp., antenna: $8-N$. solodovnikovi Grichanov, sp.n.; $9-N$. meironensis Grichanov, sp.n.

Рис. 8-9. Neurigona spp., усик: $8-N$. solodovnikovi Grichanov, sp.n.; $9-N$. meironensis Grichanov, sp.n.

Wing: hyaline, with apical projection bearing deep black round spot as figured, with apical half distinctly broader than basal half, veins brown. Apical part of vein $\mathrm{R}_{4+5}$ convex anteriad, vein $\mathrm{M}_{1+2}$ weakly sinuate at middle of distal part and at wing margin, cell $R_{4+5}$ at widest point 2 times as wide as distance between tips of $\mathrm{R}_{4+5}$ and $\mathrm{M}$; $\mathrm{M}$ joining costa far before wing apex; Ratio of cross-vein $m$-cu to distal part of $\mathrm{CuA}_{1}, 10 / 34$. Anal vein distinct, almost reaching to wing margin; anal lobe present; anal angle right. Calypter yellow, with pale cilia. Halter yellow.

Abdomen: brownish yellow with yellow pollen; tergite 1 wholly yellow; tergites $2-3$ mainly yellow, brown basolaterally; tergites $4-5$ brown; hypopygium black. Abdominal segment 5 with black ventral projection. Hairs and bristles on tergites chiefly black, ventrum and segments 5-8 with pale hairs.

Genitalia: epandrium as long as wide; 2 epandrial processes apicoventrally, each bearing apical seta. Surstylus with wide dorsal and ventral lobes; ventral lobe with wide process ending with a hook and bearing a long flattened apical seta. Cercus somewhat round, white, bearing short white hairs.

Female. Body length $3.5 \mathrm{~mm}$, wing length $3.8 \mathrm{~mm}$. Similar to male except lacking male secondary sexual characters. Eyes wider separated on face; upper face about as wide as postpedicel height. Wing: wholly hyaline, simple; with middle portion broader than apical portion, veins brown; 4th section of costa about 5 times as long as 5 th one. Fore coxa with 3-4 black bristles on antero-apical portion; fore tibia with 1 anterodorsal at basal 1/4, with black setulae except ventral surface at apex; fore tarsus simple, brownish to brown from tip of basitarsus. Fore leg length ratio (from tibia to tarsomere 5): 63/36/19/11/ 8/6. Abdomen: with segment 1 yellow; segments $2-5$ orangeyellow. Tergite $9+10$ long, narrow, brownish at base, black at apex, bifurcated, with long brownish hairs.

DIAGNOSIS. Very close to $N$. punctifera. Wing with apical projection bearing deep black round spot; $\mathrm{M}_{1+2}$ sinuate; wing vein $\mathrm{CuA}_{1}$ without punctiform thickening at wing margin. Fore tarsomere 4 with basal half somewhat swollen and with dense pale hairs; fore tarsomere 5 with one elongated claw. $N$. punctifera male has less distinct brown spot at wing apex; straight $\mathrm{M}_{1+2}$; punctiform thickening at extreme apex of $\mathrm{CuA}_{1}$, different fore leg and hypopygium morphology (Figs 7, 11, 15). Female of $N$. solodovnikovi has hyaline wing, being probably very close to female of $N$. punctifera (not studied).
ETYMOLOGY. This species named after the Russian entomologist Dr. Alexey Solodovnikov.

\section{Neurigona meironensis Grichanov, sp.n.}

(Figs 3-4, 9, 12, 16)

TYPE MATERIAL. Holotype $0^{7}$, Israel: Mt. Meiron, 17.V.1976, A. Freidberg [TAU]. Paratypes: 1 , the same locality as holotype; $10^{7}$, Israel: Mt. Meiron $(900 \mathrm{~m}), 28 . V .1981$, A. Freidberg; 1 ,

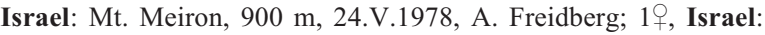
Upper N. Keziv, 3.V.1983, A. Freidberg [TAU].

DESCRIPTION. Male. Length (mm): body 5.0-5.5, wing 5.0 , antenna 1.0, hypopygium 0.9 . Head metallic green with pale grey pollen; face black with dense pale pollen. Face very narrow, nearly parallel-sided. One pair of ocellars black and strong, 1 pair of verticals black and strong, 1 pair of postverticals white, long and strong, postverticals shorter than verticals; postocular bristles entirely pale. Antenna yellow; postpedicel about as long as wide; stylus brown, middorsal, $5 \mathrm{x}$ longer than postpedicel, with short basal segment. Proboscis dirty yellow with pale hairs; palpus yellow with pale hairs.

Thorax: dark metallic green with pale grey pollen; scutellum yellow to light-brown with more or less small basal black spot at suture; metapleuron dirty yellow to dark-brown. Hairs and bristles on thorax mainly black. 6 long strong dorsocentrals, 9-10 paired acrostichals, 1 long humeral bristle and 2 short adjacent pale hair, 1 sutural, 2 notopleural, 2 supraalar bristles. Propleuron with 1-2 pale hairs on upper portion (proepimeron) and 1 yellow bristle on lower portion (proepisternum). Scutellum with 2 pairs of bristles, apical pair long and strong, but basal pair short and hair-like.

Legs: yellow; coxae yellow to brownish-yellow; fore tibia slightly darkened in distal half; fore tarsus deep black from middle of basitarsus; mid and hind tarsomeres 4-5 brownish to brown. Hairs and bristles on legs mainly black. Fore coxa with pale hairs and 3-4 yellow bristles on anteroapical portion; mid coxa with mainly yellow hairs and 2-3 yellow anterior and apical bristles; hind coxa with 1 black outer bristle at middle. All femora with sparse microscopic pale hairs ventrally. Fore tibia devoid of bristles, with normal vestiture, but with additional ventral row of minute pale erect hairs; mid tibia with 2-3 anterodorsal, 1-2 posterodorsal, 23 anteroventral, 2-3 posteroventral, 3 apical black bristles, all short; hind tibia with $0-1$ anterodorsal, $2-3$ posterodorsal, 3-4 ventral short setae, apically with yellow comb of hairs and 3 black bristles. Fore tarsus densely covered with short setulae, with somewhat denser ones on segment 2 posteriorly; tarsomere 4 flattened ventrally; tarsomere 5 apically with one short black anterior claw and 1-2 simple black posterior spinules (all less then half length of tarsomere 5) and 2 apicodorsal setae (about half as long as tarsomere 5). Mid tarsomere 1 shorter than tibia, with 6-7 short ventrals. Hind tarsomeres 1-3 each with short ventrals; hind tarsomere 1 apically with yellow comb of hairs. Fore leg length ratio (from tibia to tarsomere 5): 63/48/11/10/9/8, mid leg: 75/64/ 20/13/8/7, hind leg: 110/26/32/18/11/8.

Wing: mostly hyaline, fumose in distal $1 / 5$ or $1 / 6$, brownish around tips of $\mathrm{R}$ and $\mathrm{M}$ veins, with apical half distinctly broader than basal half; veins brown. Vein straight, weakly sinuate at apex, apical part of vein $\mathrm{M}_{1+2}$ straight in basal 5/9, then strongly bent towards $\mathrm{R}_{4+5}$, weakly sinuate at apex; cell $\mathrm{R}_{4+5}$ at widest point 8 times as wide as distance between tips of $\mathrm{R}_{4+5}$ and $\mathrm{M}$; $\mathrm{M}$ joining costa far before wing apex; Ratio of cross-vein $m$-cu to distal part of $\mathrm{CuA}_{1}, 11 / 28$. Anal vein distinct, almost reaching to wing margin; anal lobe present; anal angle right. Calypter yellow, with pale cilia. Halter yellow. 


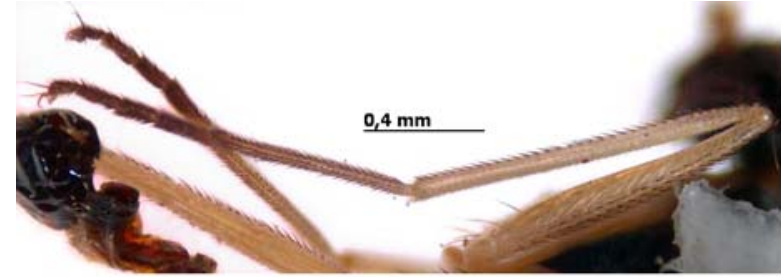

10

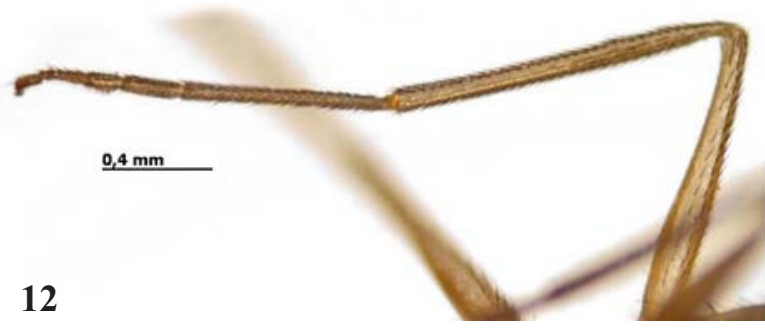

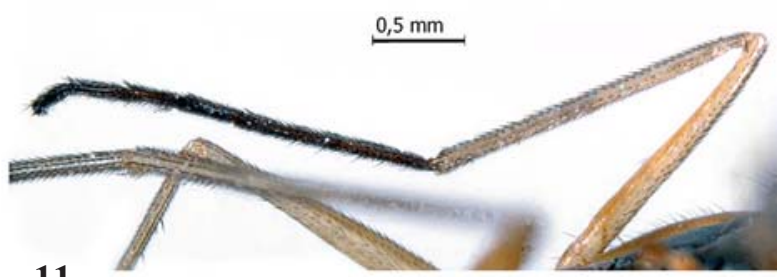

11

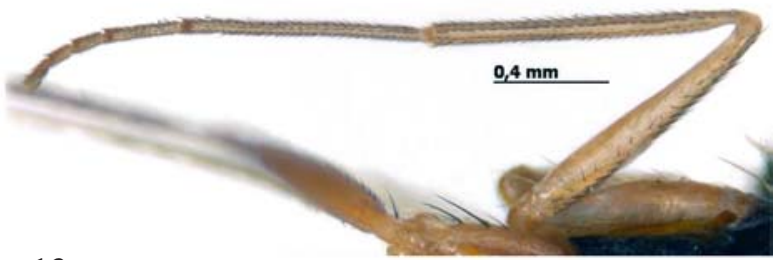

13

Figs 10-13. Neurigona spp., male fore leg: $10-N$. solodovnikovi Grichanov, sp.n.; $11-N$. punctifera Becker; $12-$ N. meironensis Grichanov, sp.n.; $13-N$. nubifera (Loew).

Рис. 10-13. Neurigona spp., передняя нога самца: $10-N$. solodovnikovi Grichanov, sp.n.; $11-N$. punctifera Becker; $12-N$. meironensis Grichanov, sp.n.; $13-N$. nubifera (Loew).

Abdomen: slightly shining, with light pollen; tergite 1 wholly yellow; tergite 2 mainly yellow, with black band at middle; tergite 3 mainly orange-yellow, with black band in basal 1/3; tergite 4 either same as tergite 3 or entirely black; segment 5 dark-yellow with black ventral projection; hypopygium black. Hairs and bristles on tergites chiefly black, ventrum and segments 5-8 with pale hairs.

Genitalia: Epandrium as long as wide; 2 epandrial processes apicoventrally, each bearing apical seta. Surstylus with wide oval dorsal and rectangular ventral lobes; dorsal lobe with rounded projection; ventral lobe of surstylus with wide process ending with a hook and bearing 2 long flattened apical setae of unequal length. Cercus somewhat rounded, white, bearing short white hairs.

Female. Body length $4.6 \mathrm{~mm}$, wing length $4.6 \mathrm{~mm}$. Similar to male except lacking male secondary sexual characters. Eyes wider separated on face; upper face about as wide as postpedicel height. Wing: simple, mostly hyaline, smoky between $\mathrm{R}_{4+5}$ and $\mathrm{M}_{1+2}$; with middle portion broader than apical portion, veins brown; $M_{1+2}$ with gentle curvation; 4th section of costa about 6 times as long as 5th one. Fore coxa with 3-4 yellow and black bristles on antero-apical portion; mid coxa with black anterior and apical bristles; fore tibia with 1 anterodorsal at basal $1 / 4$, with black setulae; fore tarsus simple, yellow, with brownish segments $4-5$. Fore leg length ratio (from tibia to tarsomere 5): 52/33/16/11/8/7. Abdomen: with segment 1 yellow; segments $2-5$ orangeyellow, each with black ring in basal $1 / 3$. Tergite 9+10 long, narrow, orange at base, blackish at apex, bifurcated, with long brownish hairs.

DIAGNOSIS. Very close to $N$. nubifera. Wing fumose in distal $1 / 5$ or $1 / 6$, brownish around tips of $R$ and $M$ veins, with apical half distinctly broader than basal half; apical part of vein $\mathrm{M}_{1+2}$ straight in basal $5 / 9$, then strongly bent towards $\mathrm{R}_{4+5} ; \mathrm{M}$ joining costa far before wing apex. Fore tarsus deep black from middle of basitarsus; fore tarsomere 4 flattened ventrally; tarsomere 5 apically with one short anterior claw. $N$. nubifera male has distinct brown spot at wing apex mainly; $\mathrm{M}_{1+2}$ is weakly sinuate at middle, joining costa just before wing apex; fore leg is yellow and simple; hypopygium has different morphology (Figs 6, 13, 17). Female of N. meironensis is very close to female of $N$. nubifera, differing in stronger curvation of $\mathrm{M}$ vein (Fig. 3).

ETYMOLOGY. The species is named for the region of origin.

\section{Neurigona suturalis (Fallén, 1823)}

Neurigona verrichterae Negrobov et Fursov, 1988, syn. nov. MATERIAL EXAMINED. 10', Dania, 32UOG57, Bjergsted Bkr. NWZ, 25-30.VI.1977, S. Andersen \& V. Michelsen leg. [ZMUC]; $30^{7}$, [Krasnodar Terr.:] Krasnaya Polyana, Pslukh cordon, 7.VI.1978 (V.Rikhter) [ZIN].

REMARK. The author was lucky to find in ZIN collection 3 topotype males with the same label as types of $N$. verrichterae described by Negrobov \& Fursov [1988]. They are identical to the description of this species, but coming to $N$. suturalis in known keys to Palearctic Neurigona species [Parent, 1938; Negrobov \& Fursov, 1988; Grichanov, 2007]. Those topotypes have no significant difference from the $N$. suturalis species concept, as well as from Danish and Swedish $N$. suturalis specimens (examined). So, we consider the two names as synonyms.

\section{Key to West-Palearctic species of the Genus NEURIGONA RoNDANI}

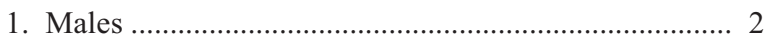

— Females .................................................................... 21

2. Some of apical segments of fore tarsus modified, enlarged or plumose ............................................................ 3

- Apical segments of fore tarsus simple; sometimes $4-5^{\text {th }}$ segments slightly enlarged, flattened or curved .......... 5

3 . Fifth segment of fore tarsus broad, triangular, black, shortsetose along margins; $2^{\text {nd }}-4^{\text {th }}$ segments of same tarsus simple, yellow; $6.0 \mathrm{~mm}$ longipes

— Fifth segment of fore tarsus simple or weakly modified; at least $4^{\text {th }}$ segment of same tarsus plumose ..................... 4

4. Mesonotum yellow, shining; $4^{\text {th }}$ and $5^{\text {th }}$ segments of fore tarsus long plumose at apex, with anterior setae more developed; 5 th segment black; 3rd one without plumage; 5.0-5.4 ............................................ pseudolongipes 

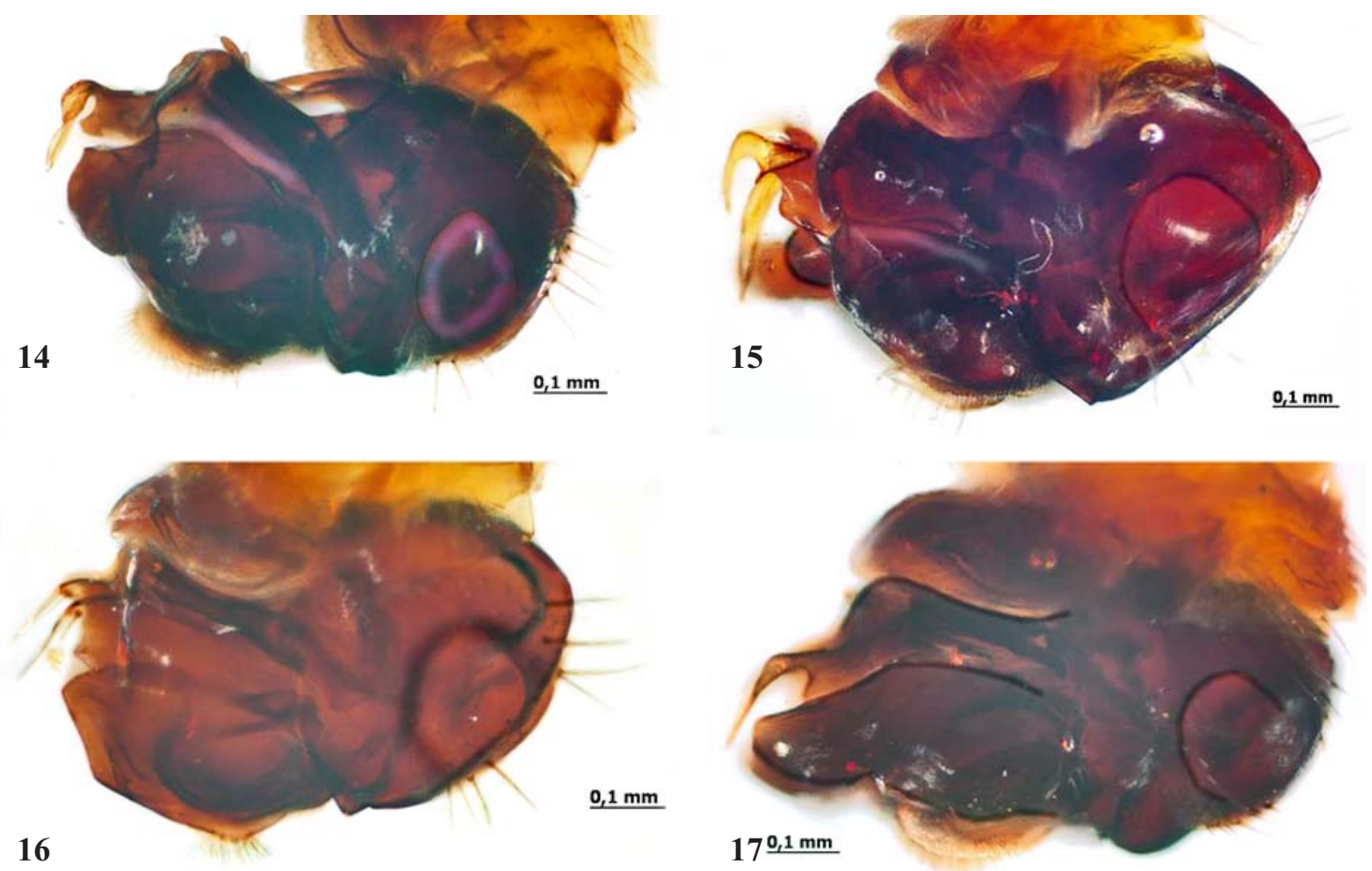

Figs 14-17. Neurigona spp., hypopygium: $14-N$. solodovnikovi Grichanov, sp.n.; $15-N$. punctifera Becker; $16-N$. meironensis Grichanov, sp.n.; $17-N$. nubifera (Loew).

Рис. 14-17. Neurigona spp., гипопигий: $14-$ N. solodovnikovi Grichanov, sp.n.; $15-$ N. punctifera Becker; $16-N$. meironensis Grichanov, sp.n.; $17-$ N. nubifera (Loew).

- Mesonotum matt-dark, covered with yellowish-grey or brownish-grey pollen; $3^{\text {rd }}$ and $4^{\text {th }}$ segments of fore tarsus black, bilaterally plumose; $5^{\text {th }}$ segment of same tarsus white, without plumage; hypopygium pedunculate; 3.5$5.0 \mathrm{~mm}$ quadrifasciata

5. Mesonotum yellow, usually slightly shining, without pollen ......

- Mesonotum mainly matt-dark, covered with yellowishgrey or brownish-grey pollen ..................................... 10

6. Abdominal $5^{\text {th }}$ tergite short, with distinct lateral lobe directed downward

- Abdominal $5^{\text {th }}$ tergite without lobelike lateral widenings

7. Hypopygium distinctly pedunculate; $3 \mathrm{rd}$ and 4 th tergites with lobelike lateral widenings; $5^{\text {th }}$ tergite having lobes black at apex; mid femur with black flat ventral setae at base; 6.0 ........................................................ pallida

- Hypopygium sessile; $3^{\text {rd }}$ and $4^{\text {th }}$ tergites without lobelike lateral widenings; mid femur without black flat ventral setae at base

8. Wing anal lobe undeveloped; $1^{\text {st }}$ abdominal segment main ly brown; 4.9 ..................................................... helva

- Wing anal lobe well developed; anal angle almost right; $1^{\text {st }}$ abdominal segment mainly yellow, brown dorsally; 4.5 $5.0 \mathrm{~mm}$ uralensis

9. Abdomen with dark longitudinal stripe; hypopygium yellow at base ................................................. lineato

- Abdominal tergites with dark transverse bands along anterior margin; fore tarsus short, $1 / 4$ shorter than fore tibia; hypopygium sessile, shining black; $4.0-4.5 \mathrm{~mm}$

erichsoni

10. Wing with dark spot at apex 11
- Wing without dark spot at apex, sometimes slightly darkened anteriorly

11 . Wing broadly smoky at apex, with regularly rounded distal margin ..................................................... 12

— Wing with distinct blackish stigma on somewhat projected

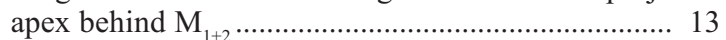

12. $\mathrm{M}_{1+2}$ almost straight; $3.5-4.0 \mathrm{~mm}$................... nubifera - $\mathrm{M}_{1+2}$ with angular curvation at apex .......... meironensis

13. $\mathrm{CuA}$, with punctiform thickening at wing margin; $4.0-5.0$ $\mathrm{mm}$........................................................... punctifera

- $\mathrm{CuA}_{1}$ simple .......................................... solodovnikovi

14. Abdomen mainly yellow ……................................... 15

- At least some of abdominal tergites with large black triangular spot reaching 2/3 length of segment......... 16

15. $\mathrm{M}_{1+2}$ straight or nearly straight; $\mathrm{R}_{4+5}$ and $\mathrm{M}_{1+2}$ almost parallel; wing darkened, darker along anterior margin; $5^{\text {th }}$ segment of fore tarsus weakly modified; 4.0-5.0 .

.. suturalis

- $\mathrm{M}_{1+2}$ strongly curved at middle of distal part; $\mathrm{R}_{4+5}$ and $\mathrm{M}_{1+2}$ converging; fore tarsus with very long anterior and short posterior claws; $5^{\text {th }}$ segment of the same tarsus with strong curved ventral setae; $4.0-5.0 \mathrm{~mm}$............ abdominalis

16. $5^{\text {th }}$ segment of fore tarsus with small but strong black ventral spines

$-5^{\text {th }}$ segment of fore tarsus without ventral spines ........ 20

17. Fore basitarsus with a group of hairs at base, more than 2 times as long as diameter of segment; fore tarsus with erect ventral hairs; mid femur with dense light ventral hairs, half as long as diameter of femur; 4.0-5.0 $\mathrm{mm}$... cilipes 
- Fore basitarsus without a group of long hairs at base; mid femur without long ventral hairs ............................ 18

18. Wing anal lobe weakly developed; vein $m$-cu 2.5 times as long as anal lobe and more than 5 times as long as distal part of $\mathrm{CuA}_{1} ; 2^{\text {nd }}$ tergite in basal $2 / 3$ and $3^{\text {rd }}$ and $4^{\text {th }}$ tergites in basal $1 / 2$ each with large black triangular spot; palpus white; $4.4-4.5 \mathrm{~mm}$.................................. subcilipes

- Wing vein $m$-cu not more than 1.5 times as long as anal lobe and about 4 times as long as distal part of $\mathrm{CuA}_{1}$; at least $3^{\text {rd }}$ and $4^{\text {th }}$ tergites in basal $1 / 3$ each with brown band having median emargination

19. Palpus yellow; $2^{\text {nd }}$ tergite in basal $1 / 3$ with brown band having median emargination; last two segments of fore tarsus equal in length; 4.6-4.9 $\mathrm{mm}$............... semilata

- Palpus white; $2^{\text {nd }}$ tergite in basal $2 / 3$ with brown triangular spot; $4^{\text {th }}$ segment of fore tarsus about half as long as 5 th one; $4.9 \mathrm{~mm}$ febrilata

20 . Fore tarsus slightly thickened, entirely black, equal to or slightly longer than fore tibia biflexa

- Fore tarsus yellow, about 1.5 times longer than fore tibia; $4^{\text {th }}$ and $5^{\text {th }}$ segments of fore tarsus slightly thickened; 4.9 $\mathrm{mm}$ dobrogica

21. Mesonotum yellow, sometimes with dark spots ...... 22

- Mesonotum mainly dark ..................................... 27

22. Mesonotum matt ............................................... 23

- Mesonotum shining ........................................... 24

23. 6 pairs of dorsocentral setae; abdominal tergites each with black band at base having median emargination; smaller: 3.5-4.0 $\mathrm{mm}$...................................... quadrifasciata

- 7 pairs of dorsocentral setae; abdomen including $5^{\text {th }}$ segment yellow; larger: 6.0 ................................ pallida

24. Body entirely yellow; mesonotum shining; fore tarsus nearly twice longer than fore tibia; 4.0 (female only) ...

unicolor

- Body partly dark, with or without shine ................... 25

25 . Fore tarsus nearly twice longer than fore tibia longipes

- Fore tarsus at most 1.5 times longer than fore tibia.. 26

$26.4^{\text {th }}$ section of costa about 1.5 times as long as $5^{\text {th }}$ one $\ldots$ pseudolongipes

- $4^{\text {th }}$ section of costa about 3 times as long as $5^{\text {th }}$ one...... ............................................................. erichsoni

27. Vein $\mathrm{M}_{1+2}$ ending before wing apex ...................... 28

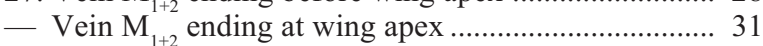

28 . Fore tibia shorter than first two tarsal segments; $4^{\text {th }}$ section of costa about 4 times as long as $5^{\text {th }}$ one; $\mathrm{M}_{1+2}$ strongly sinuate in distal part; wing hyaline ................... biflexa

- Fore tibia longer than first two tarsal segments; $4^{\text {th }}$ section of costa at least 5 times as long as $5^{\text {th }}$ one ............... 29

29. Wing hyaline; 4 th section of costa about 5 times as long as 5 th one; $\mathrm{M}_{1+2}$ weakly sinuate .............. solodovnikovi

— Wing distinctly smoky at apex ............................. 30

30. $4^{\text {th }}$ section of costa about 6 times as long as $5^{\text {th }}$ one; $M_{1+2}$ strongly sinuate in distal part .....................meironensis

- $4^{\text {th }}$ section of costa about 5 times as long as $5^{\text {th }}$ one; $\mathrm{M}_{1+2}$ weakly sinuate .......................................... nubifera

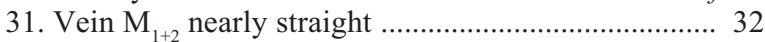

- Vein $\mathrm{M}_{1+2}^{1+2}$ curved in distal part .................................... 33

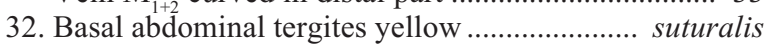

- Basal abdominal tergites with dark bands ..... subcilipes

33. Abdomen yellow; antennal postpedicel small; hind basitarsus whitish abdominalis

- Abdominal tergites with black spot ... 34

34. Antennal postpedicel large, higher than long; hind tarsus entirely black cilipes

- Antennal postpedicel longer than high; hind tarsus slightly darkened.
ACKNOWLEDGMENTS. The work was undertaken in the Zoological Museum of Copenhagen University (ZMUC) and was supported by the IAMONET-RU programme. We would like to thank Dr. Thomas Pape (ZMUC), Dr. Amnon Freidberg (TAU) and Dr. Emilia Nartshuk (ZIN) for the loan of specimens. Anonymous reviewers kindly reviewed earlier drafts of the manuscript.

\section{References}

Becker T. 1907. Die Ergebnisse meiner dipterologischen Frühjahrsreise nach Algier und Tunis 1906 // Zeitschrift für systematische Hymenopterologie und Dipterologie. No.2. S.97-128.

Becker T. 1918. Dipterologische Studien. Dolichopodidae. A. Paläarktischen Region // Nova Acta Academiae Caesareae Leopoldinisch-Carolinae Germanicae Naturae Curiosorum. No.103. S. 203-315.

Bezzi M. 1903. Orthorrhapha Brachycera // T. Becker, M. Bezzi, J. Bischof, K. Kertész \& P. Stein (eds.). Katalog der paläarktischen Dipteren. Vol.2. Budapest. P.1-396.

Cumming J.M., Wood D.M. 2009. Adult morphology and terminology [Chapter] 2 // B.V. Brown, A. Borkent, J.M. Cumming, D.M. Wood, N.E. Woodley \& M.A. Zumbado (eds.). Manual of Central American Diptera. Vol.1. NRC Research Press, Ottawa, Ontario, Canada. P.9-50.

Czerny L., Strobl G. 1909. Spanische Dipteren. III Beitrag // Verhandlungen der Kaiserlich-Königliche Zoologisch-botanischen Gesellschaft in Wien. Bd.5(59). P.121-301.

Fabricius J.C. 1781. Species insectorum, exhibentes eorum differentias specificas, synonyma auctorum, loca natalia, metamorphosin, adjectis observationibus, descriptionibus. Tome 2 . Hamburgi et Kilonii: impensis C.E. Bohnii. P.1-517.

Fallén C.F. 1823. Monographia Dolichopodum Sveciae. Lundae [=Lund]. $24 \mathrm{p}$.

Grichanov I.Ya. 2000. Afrotropical Neurigoninae and notes on the diaphorine genus Dactylonotus Parent (Diptera: Dolichopodidae) // Belgian Journal of Entomology. No.2. P.257-271.

Grichanov I.Ya. 2006c. A preliminary list of Dolichopodidae (Diptera) types in the collections of Swedish Museums // An International Journal of Dipterological Research. Vol.17. No.3. P.177-204.

Grichanov I.Ya. 2007. A checklist and keys to Dolichopodidae (Diptera) of the Caucasus and East Mediterranean // Plant Protection News Supplement. All-Russian Institute of Plant Protection, St. Petersburg. P.1-160.

Loew H. 1857. Neue Beiträge zur Kenntniss der Dipteren. Fünfter Beitrag. Programme der Königlichen Realschule zu Meseritz. S. $1-56$.

Loew H. 1869. Systematische Beschreibung der bekannten europäischen zweiflügeligen Insecten. Von Johann Wilhelm Meigen. Achter Theil oder zweiter Supplementband. Beschreibungen europäischer Dipteren. Erster Band. H.W. Schmidt, Halle. S.xvi $+1-310+1$.

Macquart J. 1827. Insectes diptères du nord de la France. Platypézines, dolichopodes, empides, hybotides. Lille. P.1-159.

Naglis S. 2003. Revision of the Neotropical Neurigoninae (Diptera: Dolichopodidae) V: Neurigona Rondani // Studia dipterologica. Vol.10. No.1. P.267-314.

Negrobov O.P. 1987. New paleartctic species of the dolichpodid flies of the genus Neurigona Rond. (Diptera, Dolichopodidae) // Entomologicheskoe obozrenie. Vol.66. No.2. P.406415 [in Russian].

Negrobov O.P., Fursov V.N. 1988. Revision of the palearctic species of Neurigona Rond. (Diptera, Dolichopodidae) // Entomologicheskoe obozrenie. Vol.67. No.2. P.405-416 [in Russian; Engl. transl.: Entomological Review. Vol.68(1), 139-152].

Negrobov O.P., Tsurikov M.N. 1990. New species of the genus Neurigona Rondani (Diptera, Dolichopodidae) from Caucasus // Nauchnye doklady vysshei shkoly. Biologicheskie nauki. No.10. P.35-37. 
Oldenberg L. 1904. Die Gattung Saucropus Lw. (Dipt.) // Zeitschrift für systematische Hymenopterologie und Dipterologie.No.4. P.65-81.

Oldenberg L. 1916. Einige Dolichopodiden meiner Ausbeute (Dipt.) // Entomologische Mitteillungen. Bd.5. H.5/8. S.187198.

Pârvu C. 1996. Neurigona dobrogica n. sp. (Diptera: Dolichopodidae) and some others species recorded for the first time in Romania (XI) from its southern half // Travaux du Museum d'Historie Naturelle "Grigore Antipa" . Vol.36. P. 265-277
Rondani C. 1856. Dipterologiae Italicae prodromus. Vol: I. Genera Italica ordinis dipterorum ordinatim disposita et distincta et in familias et stirpes aggregata. A. Stocchi, Parmae. P.1-226 + [2]

Schiner I.R. 1862. Die Fliegen (Diptera) // L. Redtenbacher \& I.R. Schiner (eds.). Fauna Austriaca. Bd.1. 674 S.

Wang M., Yang D., Grootaert P. 2007. Notes on the Neurigona Rondani (Diptera: Dolichopodidae) from Chinese Mainland // Zootaxa. No.1388. P.25-43.

Zetterstedt J.W. 1843. Diptera Scandinaviae disposita et descripta. Officina Lundbergiana, Lundae [= Lund] . Vol.2. P.441-894. 